\title{
Adenocarcinoma arising from a long-standing solitary rectal ulcer syndrome
}

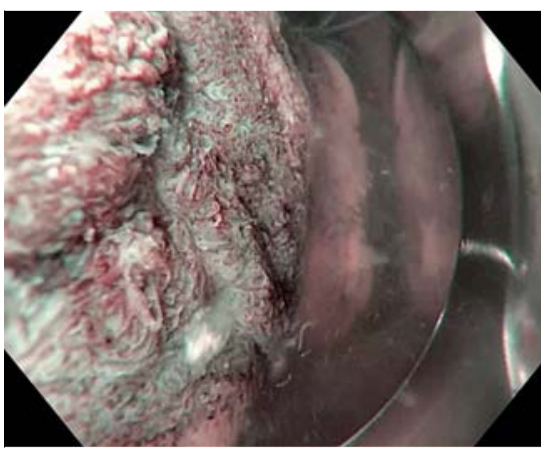

- Fig. 1 Rectal Paris 0-Is lesion presenting some areas of irregular pit pattern (Kudo $\mathrm{Vn}$ ) and vascular pattern (Sano IIIb).

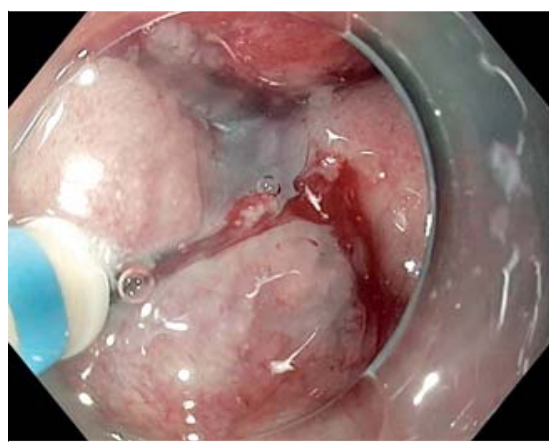

- Fig. 2 Circumferential incision of the mucosa was performed around the lesion.

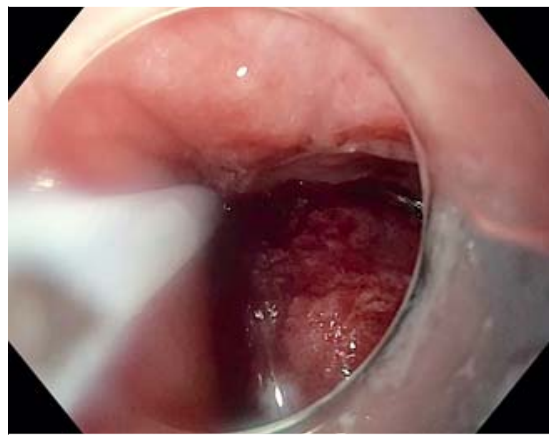

Fig. 3 The hot snare was placed into the incision and the lesion was removed using a hybrid resection technique.

Solitary rectal ulcer syndrome (SRUS) is a rare chronic disease characterized by a combination of clinical symptoms, endoscopic appearance, and histology find-

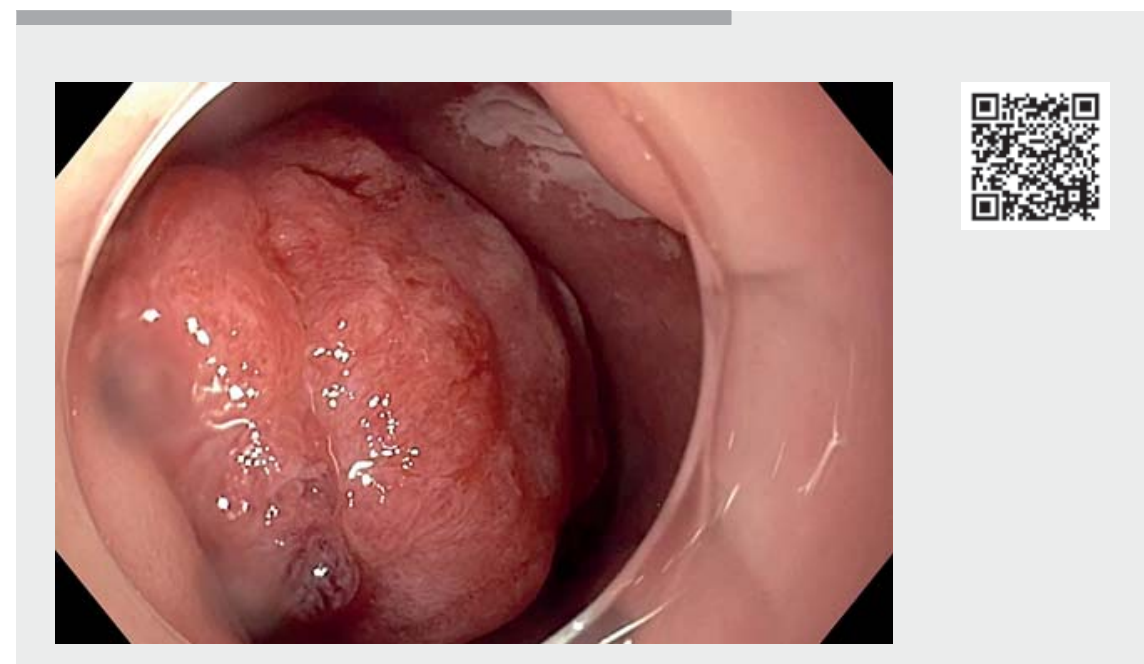

Video 1 Adenocarcinoma arising from a long-standing solitary rectal ulcer syndrome.

ings, with periods of remission and relapse [1,2]. It most commonly affects young adults [3]. Patients usually pass mucus and blood while defecating, but can also complain about tenesmus, straining on defecation, incontinence, or a sensation of incomplete evacuation [4]. SRUS is a benign condition, but some rare cases of associated adenocarcinomas have been described [5].

We report here the case of a 57 -year-old woman with a history of a long-standing SRUS refractory to two surgical operations. After the second operation, a polypoid lesion appeared which was consistent with a cicatricial lesion. Five years later, endoscopic reevaluation revealed that the lesion had increased in size, and low-grade dysplasia was shown on biopsies. The patient was therefore sent to our endoscopy unit for resection of this lesion ( $\vee$ Video 1$)$.

Endoscopy revealed a Paris 0-Is lesion; its base presented an adenomatous appearance, but in other parts there were some areas of irregular pit pattern (Kudo Vn) and vascular pattern (Sano $\mathrm{IIIb}$ ) that could be consistent with adenocarcinoma or an inflammatory lesion ( $\bullet$ Fig. $\mathbf{1}$ ). Because of this appearance, en bloc re- section of the lesion was decided upon, using a hybrid resection technique. Circumferential incision of the mucosa was performed around the lesion ( $\bullet$ Fig. 2 ). Then, the hot snare was placed into the incision and the lesion was removed ( $\triangleright$ Fig.3). A residual part was removed with the hot snare. The pathology report showed moderately differentiated adenocarcinoma infiltrating the submucosa by more than $5000 \mu \mathrm{m}$ within an inflammatory stroma. The resection was not R0 and the patient underwent radiotherapy and proctectomy.

This case highlights the fact that we should be careful when we encounter a lesion in the setting of long-standing SRUS, and should consider resection.

Endoscopy_UCTN_Code_CCL_1AD_2A

\section{Competing interests}

The authors declare that they have no conflict of interest. 
The authors

Thomas Lambin ${ }^{1,2}$, Pierre Lafeuille ${ }^{1}$, Jérôme Rivory ${ }^{1}$, Florian Rostain ${ }^{1}$, Martin Fabritius ${ }^{1}$, Eddy Cotte $^{3}$, Mathieu Pioche ${ }^{1,2}$

1 Gastroenterology and Endoscopy Unit, Pavillon L, Edouard Herriot Hospital, Lyon, France

2 Inserm U1032, Labtau, Lyon, France

3 Department of Gastrointestinal Surgery, Hospices Civils de Lyon, Université de Lyon, Centre Hospitalier Lyon-Sud, Lyon, France

\section{Corresponding author}

\section{Thomas Lambin, MD}

Endoscopy Unit, Digestive Disease Department, Pavillon L, Edouard Herriot Hospital, 69437 Lyon Cedex, France thomaslambin@hotmail.fr

\section{References}

[1] Zhu Q-C, Shen R-R, Qin H-L et al. Solitary rectal ulcer syndrome: clinical features, pathophysiology, diagnosis and treatment strategies. World J Gastroenterol 2014; 20: 738-744

[2] Gouriou C, Siproudhis L, Chambaz M et al. Solitary rectal ulcer syndrome in 102 patients: Do different phenotypes make sense? Dig Liver Dis 2021; 53: 190-195

[3] Madigan MR, Morson BC. Solitary ulcer of the rectum. Gut 1969; 10: 871-881

[4] Sharara Al, Azar C, Amr SS et al. Solitary rectal ulcer syndrome: endoscopic spectrum and review of the literature. Gastrointest Endosc 2005; 62: 755-762

[5] Abid S, Khawaja A, Bhimani SA et al. The clinical, endoscopic and histological spectrum of the solitary rectal ulcer syndrome: a single-center experience of 116 cases. BMC Gastroenterol 2012; 12: 72
Bibliography

Endoscopy 2022; 54: E205-E206

DOI $10.1055 / a-1486-6253$

ISSN 0013-726X

published online 12.5.2021

(c) 2021. Thieme. All rights reserved.

Georg Thieme Verlag KG, Rüdigerstraße 14, 70469 Stuttgart, Germany

\section{ENDOSCOPY E-VIDEOS}

https://eref.thieme.de/e-videos

口过 Endoscopy E-Videos is an open access online section, 甶程: reporting on interesting cases and new techniques in gastroenterological endoscopy. All papers include a high quality video and all contributions are freely accessible online. Processing charges apply (currently EUR 375), discounts and wavers acc. to HINARI are available.

This section has its own submission website at https://mc.manuscriptcentral.com/e-videos 